\title{
Focus on exposure to air pollution and related health impacts
}

\author{
Otto Hänninen • Sotiris Vardoulakis • \\ Dimosthenis A. Sarigiannis • Selahattin Incecik • \\ Ranjeet S. Sokhi
}

Published online: 25 February 2011

(C) Springer Science+Business Media B.V. 2011

Outdoor and indoor air pollution was recently identified as a key contributor to the environmental burden of disease in European countries (EBoDE Working Group 2011). Due to the time-activity profiles of contemporary lifestyles, most human exposure to both indoor and ambient air pollutants takes place indoors. Buildings partly protect occupants, but nevertheless outdoor air pollution penetrates enough to result in sustained and sometimes high daily exposures to certain air pollutants. Indoor air pollution sources, e.g. domestic heating, cigarette smoking and cooking devices, can also contribute significantly to the total personal exposure to gases and fine particles. These exposures are in addition to short-term exposures to pollutants generated in traffic and other more polluted microenvironments. The role of the indoor environment is highlighted, e.g. by the

This is a special issue from the Conference on Air Quality-Science and Application, Istanbul, 24-27 March 2009, Special Session on Exposure and Health Impacts of Air Pollution.

O. Hänninen $(\bowtie)$

National Institute for Health and Welfare,

Kuopio, Finland

e-mail: otto.hanninen@thl.fi

S. Vardoulakis

Health Protection Agency,

London, UK

D. A. Sarigiannis

Aristotle University of Thessaloniki,

Thessaloniki, Greece

S. Incecik

Istanbul Technical University,

Istanbul, Turkey

R. S. Sokhi

University of Hertfordshire,

Hertfordshire, UK recent publication of WHO Guidelines for Indoor Air Quality (WHO 2010), and roughly half of the burden of disease caused by poor indoor air quality in European countries was associated with pollutants originating from outdoor air (de Oliveira Fernandes et al. 2009).

Since 1996, the series of Urban Air Quality meetings have brought together members of the European and global research communities working in the field of air quality. From the beginning of the series, the topics have covered air quality monitoring, modelling, exposure assessment and related health effects. Due to the widening scope of the meeting, the name was changed to Air Quality-Science and Application and interactions between outdoor and indoor air were included. The conference was organised by the University of Hertfordshire, UK and hosted by the Istanbul Technical University on 24-27 March 2009. From the first meeting organised in Hertfordshire, UK, the meeting has grown into a large international biennial event.

Seventeen parallel sessions took place during the 4-day event. The sessions on air quality and health and personal exposure to indoor and outdoor air pollution accepted 65 submissions from 25 countries in Europe, North America, South America and Asia. The current special double issue of Air Quality, Atmosphere, \& Health presents a number of selected manuscripts based on the original presentations from the conference. The papers cover the full exposure chain from emission sources and air quality assessment to exposure, source apportionment, health effects and risk assessment. Particulate matter is the common denominator in most of the papers. By deepening our understanding of exposure processes, the papers contribute to the goals of the journal-finding solutions for the consequences of atmospheric contamination by human activities.

Two of the papers prepared for this special issue were already published in the last issue of 2010; these papers 
presented at Air Quality 2009 are available from the journal web site (Branis and Kolomaznikova 2010; Saraga et al. 2010).

We would like to express our sincere gratitude to the authors and reviewers, whose valuable work has made it possible to bring these results at hand for the wider audience and maintain the presentation of data and results at the scientific standards of Atmosphere, Air Quality, \& Health.

The conference was supported by World Meteorological Organization and GURME, European Meteorological Society, European Association for the Science of Air Pollution, GAW Urban research Meteorology and Environment Programme, European Co-operation in Science and Technology (COST), in particular COST 728 and ES0602, the European Funded projects CAIR4HEALTH, AIR4EU, CLEAR and MEGAPOLI, TUBITAK Turkey, British Petroleum Turkey, Shell Turkey, Air \& Waste Management Society and American Meteorological Society.

\section{References}

Braniš M, Kolomazníková J (2010) Monitoring of long-term personal exposure to fine particulate matter (PM2.5). Air Qual Atmos Health 3:235-243. doi:10.1007/s11869-010-0072-9

de Oliveira Fernandes E, Jantunen M, Carrer P, Seppänen O, Harrison P, Kephalopoulos S (2009) Final activity report. EnVIE, coordination action on indoor air quality and health effects. http:// paginas.fe.up.pt/ envie/documents/finalreports/Final\%20Reports $\% 20$ Publishable/Publishable \%20final\%20activity\%20report.pdf (accessed January 19, 2011)

EBoDE Working Group (2011) European perspectives on Environmental Burden of Disease; Estimates for nine stressors in six countries. THL Reports 1/2011, Helsinki, Finland. 85 pp +2 appendixes. ISBN 978-952-245-413-3

Saraga DE, Maggos TE, Sfetsos A, Tolis EI, Andronopoulos S, Bartzis JG, Vasilakos C (2010) PAHs sources contribution to the air quality of an office environment: experimental results and receptor model (PMF) application. Air Qual Atmos Health 3:225-234. doi:10.1007/s11869-010-0074-7

WHO (2010) Guidelines for Indoor Air Quality: Selected pollutants. xxv + 454 pages. ISBN 978928900213 4. Copenhagen. http:// www.euro.who.int/_data/assets/pdf_file/0009/128169/e94535. pdf (accessed January 18, 2011) 